\title{
Explaining Organizational Citizenship Behavior Among Chinese Nurses Combating COVID-19
}

This article was published in the following Dove Press journal:

Risk Management and Healthcare Policy

\author{
Hui Zhang',* \\ Yi Zhao ${ }^{2, *}$ \\ Ping Zou (iD ${ }^{3}$ \\ Shuanghong Lin $^{2}$ \\ Shaoyu $\mathrm{Mu}^{4}$ \\ Qiansu Deng ${ }^{5}$ \\ Chunxue Du' \\ Guanglan Zhou' \\ Jiang $\mathrm{Wu}^{2}$ \\ Lu Gan ${ }^{2}$
}

'Department of Cardiology, Guizhou Provincial People's Hospital, Guiyang, 550002, Guizhou, People's Republic of China; ${ }^{2}$ Department of Nursing, Hubei NO.3 People's Hospital of Jianghan University, Wuhan, People's Republic of China; ${ }^{3}$ Department of Scholar

Practitioner Program, School of Nursing, Nipissing University, Toronto, M6] 3S3,

Ontario, Canada; ${ }^{4}$ Department of Nursing, Nursing College of Chongqing Medical University, Chongqing, 4000I6, People's Republic of China; ${ }^{5}$ Department of Nursing, Chongqing Traditional Chinese Medicine Hospital, Chongqing, 4000 I I, People's Republic of China

*These authors contributed equally to this work
Correspondence: Shuanghong Lin Department of Nursing, Hubei NO.3 People's Hospital of Jianghan University, Wuhan, People's Republic of China $\mathrm{Tel}+8618771059373$

Email1877I059373@I63.com
Background: Little is known about the associated factors with organizational citizenship behavior among Chinese nurses combating COVID-19. The aim of the present study was to investigate the relationships between autonomy, optimism, role conflict, work engagement, and organizational citizenship behavior based on moderated mediation models among Chinese nurses combating COVID-19.

Methods: This cross-sectional study was performed on a sample of 368 nurses supporting the COVID-19 epidemic in Wuhan Leishenshan Hospital, China. According to the Job DemandsResources model, two moderated mediation models were tested, in which autonomy/optimism was associated with organizational citizenship behavior through work engagement, when role conflict served as a moderator.

Results: This current study found the mediating effect of work engagement and the moderating effect of role conflict on the relationship between autonomy/optimism and organizational citizenship behavior among nurses. Of note, nurses working in the COVID-19 epidemic viewed role conflict as challenge job demands rather than hindrance job demands.

Conclusion: Based on the findings, organizational citizenship behavior can be affected by work engagement and role conflict. Nursing management is suggested to put emphasis on work engagement and role conflict among nurses supporting the COVID-19 epidemic.

Keywords: the job demands-resources model, autonomy, optimism, organizational citizenship behavior, nurses, COVID-19

\section{Introduction}

The healthcare system has been overwhelmed after the COVID-19 outbreak. Being the largest health profession, as well as the only professional at a patient's bedside in a 24-hour period, the nurse workforce plays a crucial role in the delivery of quality healthcare services for patients with COVID-19. Nurses combating COVID19 may face enormous challenges including high-level working standards and a tough work environment. These challenges may have a huge impact on nurses' organizational citizenship behavior ${ }^{1}$ which refers to a type of positive work behavior that is not explicitly part of the job description and is also not officially required by the occupation. ${ }^{2}$ A high level of organizational citizenship behaviors among nurses increases team cooperation, strengthens organizational productivity, and helps the organization respond to challenge. ${ }^{3}$ It is necessary to focus on organizational citizenship behavior among nurses deliver healthcare for patients with COVID-19.

In addition to organizational citizenship behavior, work engagement is also critical for nurses as it is related to the quality of healthcare services for 
patients. ${ }^{4}$ Employees with high levels of work engagement can be energetic, because they feel a fulfilling state of vigor and become so immersed in their work activities. ${ }^{5}$ An experimental study found that individuals with a high level of engagement are more likely to complete tasks excellently because they pay attention to the task and dedicate themselves to their work. ${ }^{6}$ Work engagement has become an important issue, so considerable attention has been paid to the antecedents of work engagement. ${ }^{7}$

Existing research has identified the antecedents of work engagement based on the Job Demands-Resources (JD-R) model. ${ }^{7}$ Drawing on the JD-R model, job resources facilitate a motivational process where resources can predict work engagement. Examples of job resources are autonomy and social support. ${ }^{1}$ Autonomy can help individuals to have flexibility and freedom when they work, improving the level and depth of their job-related knowledge. $^{8}$

The JD-R theory cannot only focus on employee wellbeing (e.g., work engagement), but also predict organizational citizenship behavior. ${ }^{9}$ Job resources can have a positive impact on job performance through work engagement based on the motivational process. ${ }^{1}$ Keyko et al found that job autonomy positively related to work engagement, leading to positive outcomes among nurses. ${ }^{10}$ However, little is known about whether work engagement may serve as a link between autonomy and organizational citizenship behavior.

Hypothesis 1. The association between autonomy and organizational citizenship behavior will be positively mediated by work engagement.

Like job resources, personal resources serve as an antecedent of work engagement. This means that personal resources indirectly affect job performance through work engagement. ${ }^{1}$ Optimism can be seen as one kind of personal resources including the willingness of an individual to experience good achievements and avoid bad events. ${ }^{11}$ When individuals are faced with challenges at work, optimism can help them look at the positive sides of the situation and overcome difficulties. ${ }^{12}$ The existing literature about the effect of optimism as personal resources has been investigated through the JD-R model. Chen (2018) reported that optimism can affect job performance via work engagement. However, few empirical investigations looking at the relationship between optimism, work engagement, and organizational citizenship behavior.
Hypothesis 2. work engagement will positively mediate the relationship between optimism and organizational citizenship behavior.

According to the JD-R theory, job demands include hindrance and challenge demands. Challenge job demands include a high workload and long working hours, while hindrance job demands include role ambiguity and role conflict. ${ }^{13}$ Role conflict refers to "the behavior of a person who is within a role need to meet the incompatible expectations". ${ }^{14}$ When nurses work in some special hospitals, they may face many challenging situations, like long hours of work and insufficient time to relax.

Drawing on the JD-R model, job resources and personal resources both have an impact on work engagement when job demands act as a moderator. ${ }^{1}$ For example, Bakker et al have found that job resources have a strong relationship with work engagement when job demands are at a high level. ${ }^{15}$ Chen et al found that the relationship between personal resources and work engagement can be moderated by job demands. ${ }^{7}$ Role conflict served as a moderator in the association between empowering leadership and exploration. ${ }^{16}$ However, the moderating effect of role conflict on the relationship between autonomy/optimism and work engagement has not been studied yet.

Hypothesis 3. The effect of autonomy on engagement will be moderated by role conflict.

Hypothesis 4. The effect of optimism on engagement will be moderated by role conflict.

It is suggested that both autonomy and optimism can affect organizational citizenship behavior through work engagement $(\mathrm{H} 1, \mathrm{H} 2)$. Additionally, it is proposed that the relationship between autonomy/optimism and engagement can be moderated by role conflict (H3, H4). Consequently, it is necessary to test moderated mediation models. This means that the effect of autonomy and optimism on organizational citizenship behavior via engagement is moderated by role conflict (Figure 1).

Hypothesis 5. The indirect effect of autonomy on organizational citizenship behavior through work engagement will be moderated by role conflict.

Hypothesis 6. The indirect effect of optimism on organizational citizenship behavior through work engagement will be moderated by role conflict. 


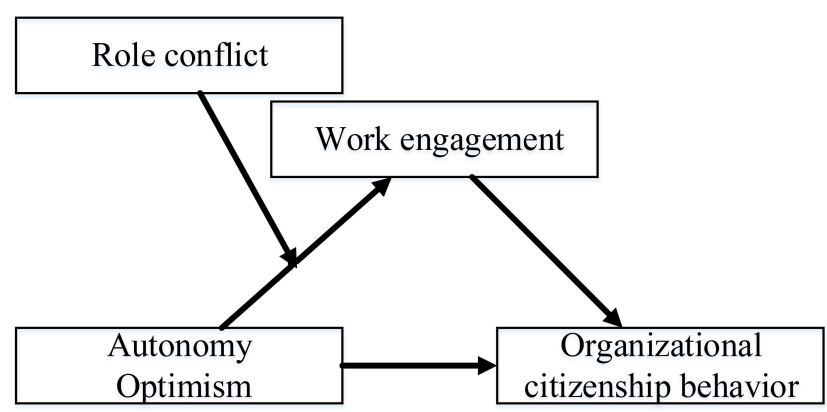

Figure I Conceptual model.

\section{Method}

\section{Study Units and Participants}

This study was conducted among nurses in March 2020. Convenience sampling was used to recruit nurses from Wuhan Leishenshan Hospital. All data were collected through electronic questionnaires that were anonymous and distributed through Wechat. The first page of the electronic questionnaire provided detailed information for participants who can provide informed consent using click-box agreements via electronic questionnaires. Those who did not agree were directed to close the online survey. This study was conducted in accordance with the Declaration of Helsinki. A total of 479 nurses were invited and 368 nurses agreed to participate and completed the electronic questionnaires.

\section{Measures}

\section{Autonomy}

Autonomy was measured with the job autonomy survey scale from the Job Diagnostic Survey developed by Hackman et al. ${ }^{17}$ The Chinese version of this scale includes three items. ${ }^{18}$ One of these items is: "Can you decide for yourself how to execute your work?"17 This scale is a 7-point scale ranging from $1=$ very little to $7=$ very much.

\section{Optimism}

A four-item scale of the Life Orientation test scale was used to measure optimism. ${ }^{19}$ We used the Chinese version of the scale in this study. ${ }^{20}$ One sample item in the short scale was, "I am always optimistic about my future". ${ }^{19}$ The participants rated each item on a 5-point scale ranging from $0=$ strongly disagree to $4=$ strongly agree.

\section{Work Engagement}

The Utrecht Work Engagement Scale-9 was used to measure work engagement. ${ }^{21}$ There are three dimensions in this scale: vigor, dedication, and absorption. Each dimension contains three items. Bakker et al have recommended the use of three dimensions to evaluate work engagement among employees. ${ }^{22}$ The Chinese version of this scale has been widely used. ${ }^{23}$ One sample item was, "At my work, I feel that I am bursting with energy". ${ }^{21}$ The participants responded to each item on a 7-point scale ranging from $0=$ never to $6=$ always.

\section{Role Conflict}

During the pandemic, nurses facing a lack of time and energy can experience a high level of role conflict as challenge job demands. ${ }^{24}$ Role conflict was assessed using the 3 -item role conflict scale. ${ }^{25}$ The Chinese version of this scale has been widely used. ${ }^{26}$ One sample item was, "I often get involved in situations in which there are conflicting requirements". ${ }^{25}$ This is a 5-point scale ranging from $1=$ completely not true to $5=$ completely true.

\section{Organizational Citizenship Behavior}

The 10-item scale developed by Bachrach et al was used to assess organizational citizenship behavior. ${ }^{27}$ There are two dimensions in this scale: helping (seven items) and civic virtue (three items). It is suggested that researchers can use two dimensions to evaluate organizational citizenship behavior among employees. ${ }^{27}$ One sample item was "Help other employees out if someone falls behind in his/her work". ${ }^{27}$ This is a 5 -point scale ranging from $1=$ completely not true to $5=$ completely true and it has been widely used in China. ${ }^{28}$

\section{Statistical Analysis}

The descriptive information, Cronbach's alpha, average variance extracted, and correlation matrix were calculated using SPSS Version 24. PROCESS macro based on ordinary least-squares regression was used in this study. ${ }^{29}$ Model 4, model 1 and model 7 of PROCESS macro were adapted to test the mediation, moderation, and moderated mediation hypotheses. The number of bootstrap samples was 5,000 in this study. Simple slope analysis was performed for probing interaction. An "index of moderated mediation" was generated by using a bootstrap confidence interval. Point estimates were significant when the bootstrap 95\% confidence interval did not contain zero.

\section{Results}

\section{Preliminary Analyses}

Table 1 presents means, standard deviations, Cronbach's alpha, average variance extracted (AVE), and 
Table I Correlation Coefficient, Mean, the Cronbach's Alpha, Standard Deviation, and AVE

\begin{tabular}{|c|c|c|c|c|c|c|c|c|c|}
\hline Variables & M & SD & Cronbach's a & AVE & I & 2 & 3 & 4 & 5 \\
\hline I. Autonomy & 5.51 & 1.39 & 0.90 & 0.76 & 0.87 & & & & \\
\hline 2. Optimism & 4.30 & 0.63 & 0.86 & 0.64 & $0.42 * *$ & 0.80 & & & \\
\hline 3. Role conflict & 2.90 & 0.97 & 0.78 & 0.68 & $-0.13^{*}$ & -0.02 & 0.82 & & \\
\hline 4. Engagement & 4.91 & 1.07 & 0.92 & 0.57 & $0.37 * *$ & $0.47 * *$ & -0.10 & 0.76 & \\
\hline 5. OCB & 5.19 & 0.78 & 0.95 & 0.70 & $0.30 * *$ & $0.49 * *$ & $-0.13^{*}$ & $0.53 * *$ & 0.83 \\
\hline
\end{tabular}

Notes: **Significant at the 0.01 level; *significant at the 0.05 level; the square of root of AVE values are bolded.

Abbreviations: OCB, organizational citizenship behavior; AVE, average variance extracted.

correlations of study variables. AVE for organizational citizenship behavior, engagement, autonomy, optimism, and role conflict was $0.70,0.57,0.76,0.64$, and 0.68 , respectively, exceeded 0.50 ; this indicated that convergent validity was satisfactory. In Table 1, the square of the root of AVE values exceeded the construct correlation values suggesting that discriminant validity is satisfactory.

\section{Mediation Analyses}

Model 4 of PROCESS macro was adapted to examine if work engagement was a mediator. The indirect effect of autonomy on organizational citizenship behavior via engagement was significant $(b=0.10, \mathrm{SE}=0.02,95 \% \mathrm{CI}=$ $[0.07,0.14])$, and the indirect effect of optimism on organizational citizenship behavior was also significant $(b=0.22, \mathrm{SE}=0.04,95 \% \mathrm{CI}=[0.15,0.31])($ Table 2$)$.

\section{Moderation Analyses}

The association between autonomy and engagement was moderated by role conflict $(\mathrm{b}=0.10, \mathrm{SE}=0.03, \mathrm{t}=3.00$, $p=0.003$ ), while the relationship between optimism and engagement was also moderated by role conflict (b $=0.21, \mathrm{SE}=0.08, \mathrm{t}=2.55, p=0.01)$. Figure 2 reveals that autonomy was more strongly related to engagement at high levels of role conflict $(b=0.37, \mathrm{SE}=0.05, \mathrm{t}=7.75$, $p<0.001)$ than at low levels of role conflict ( $\mathrm{b}=0.18$, $\mathrm{SE}=0.05, \mathrm{t}=3.63, p<0.001)$. Figure 3 reveals that optimism was more strongly related to engagement at a high level of role conflict $(\mathrm{b}=1.02, \mathrm{SE}=0.12, \mathrm{t}=8.45, p<0.001)$ than at

Table 2 Mediation Analyses

\begin{tabular}{|c|c|c|c|c|c|}
\hline DV & IV & b & SE & $\mathbf{t}$ & Bootstrap $95 \% \mathrm{Cl}$ \\
\hline OCB & $\begin{array}{l}\text { Constant } \\
\text { Autonomy } \\
\text { Engagement }\end{array}$ & $\begin{array}{l}3.09 \\
0.07 \\
0.35\end{array}$ & $\begin{array}{l}0.18 \\
0.03 \\
0.04\end{array}$ & $\begin{array}{l}17.06 * * * \\
2.58 * \\
10.19 * * *\end{array}$ & \\
\hline Engagement & $\begin{array}{l}\text { Constant } \\
\text { Autonomy }\end{array}$ & $\begin{array}{l}3.33 \\
0.29\end{array}$ & $\begin{array}{l}0.21 \\
0.04\end{array}$ & $\begin{array}{l}15.75 * * * \\
7.69 * * *\end{array}$ & \\
\hline OCB & $\begin{array}{l}\text { Constant } \\
\text { Autonomy } \\
\text { Indirect Effect I }\end{array}$ & $\begin{array}{l}4.26 \\
0.17 \\
\mathbf{0 . 1 0}\end{array}$ & $\begin{array}{l}0.16 \\
0.03 \\
\mathbf{0 . 0 2}\end{array}$ & $\begin{array}{l}26.93 * * * \\
6.08 * * *\end{array}$ & $0.07-0.14$ \\
\hline OCB & $\begin{array}{l}\text { Constant } \\
\text { Optimism } \\
\text { Engagement }\end{array}$ & $\begin{array}{l}2.19 \\
0.38 \\
0.28\end{array}$ & $\begin{array}{l}0.23 \\
0.06 \\
0.04\end{array}$ & $\begin{array}{l}9.51 * * * \\
6.48 * * * \\
8.12 * * *\end{array}$ & \\
\hline Engagement & $\begin{array}{l}\text { Constant } \\
\text { Optimism }\end{array}$ & $\begin{array}{l}1.54 \\
0.78\end{array}$ & $\begin{array}{l}0.34 \\
0.08\end{array}$ & $\begin{array}{l}4.54 * * * \\
10.05 * * *\end{array}$ & \\
\hline $\mathrm{OCB}$ & $\begin{array}{l}\text { Constant } \\
\text { Optimism } \\
\text { Indirect Effect } 2\end{array}$ & $\begin{array}{l}2.62 \\
0.60 \\
\mathbf{0 . 2 2}\end{array}$ & $\begin{array}{l}0.24 \\
0.06 \\
\mathbf{0 . 0 4}\end{array}$ & $\begin{array}{l}10.78 * * * \\
10.67 * * *\end{array}$ & $0.15-0.3 \mid$ \\
\hline
\end{tabular}

Notes: Bootstrap sample size $=5000 ;{ }^{*}<0.05$; $* * * p<0.00$ I; indirect effect I, autonomy $\rightarrow$ engagement $\rightarrow$ organizational citizenship behavior; indirect effect 2 , optimism $\rightarrow$ engagement $\rightarrow$ organizational citizenship behavior.

Abbreviations: DV, dependent variable; IV, independent variable; OCB, organizational citizenship behavior. 


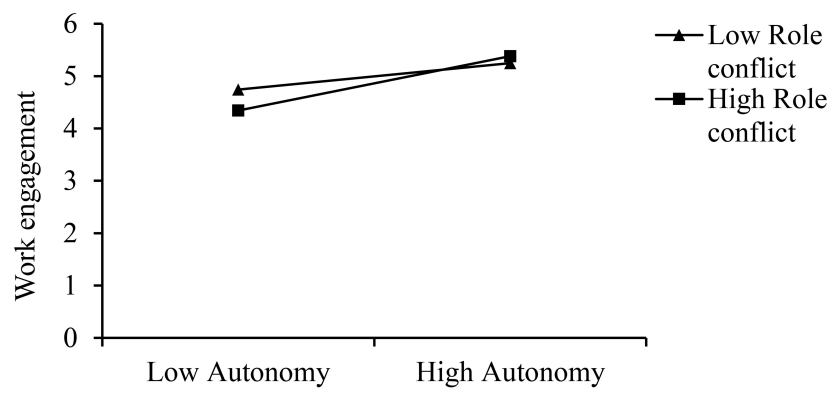

Figure 2 Role conflict as a moderator of the relationship between autonomy and work engagement.

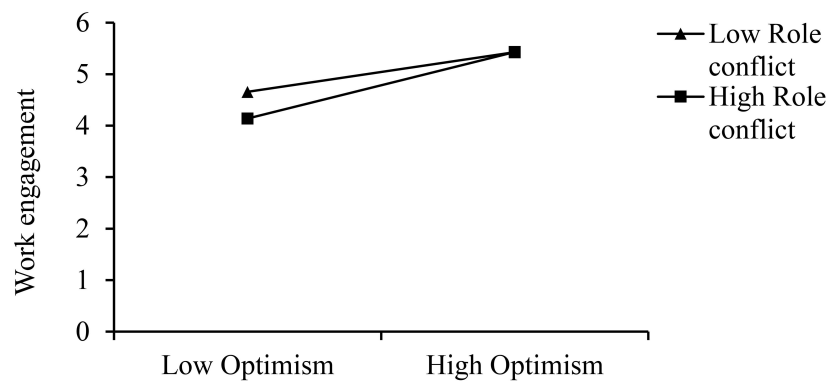

Figure 3 Role conflict as a moderator of the relationship between optimism and work engagement.

a low level of role conflict $(\mathrm{b}=0.61, \mathrm{SE}=0.10, \mathrm{t}=5.89$, $p<0.001$ ).

\section{Moderated Mediation Analyses}

The indirect effect of both autonomy and optimism on organizational citizenship behavior was strongest at the higher levels (+1 SD) of role conflict and weakest for those who were at the lowest $(-1 \mathrm{SD})$ levels of role conflict. Moderated mediation analyses showed that the confidence intervals of moderated mediation index did not contain zero (Table 3 ).

\section{Discussion}

This study aimed to explain organizational citizenship behavior among Chinese nurses combating COVID-19 in Wuhan on the basis of the JD-R model. The findings support all hypotheses.

This study suggests that autonomy can affect organizational citizenship behavior via work engagement. This finding accords with earlier research. A study found that nurses with more autonomy become more engaged, so that they have less intention to leave. ${ }^{30}$ According to the JD-R model, autonomy can help improve nurses' growth, learning and development due to its motivational effects. In such cases, nurses could become engaged, and this
Table 3 Moderated Mediation Analyses

\begin{tabular}{|l|c|c|c|c|}
\hline Values of Moderators & $\begin{array}{c}\text { Indirect } \\
\text { Effect }\end{array}$ & SE & LLCI & ULCI \\
\hline Role conflict (for & & & & \\
autonomy) & 0.06 & 0.02 & 0.02 & 0.12 \\
- ISD & 0.10 & 0.02 & 0.06 & 0.14 \\
M & 0.13 & 0.03 & 0.09 & 0.18 \\
+ I SD & 0.04 & 0.02 & 0.01 & 0.06 \\
Index of moderated & & & & \\
mediation I & & & & \\
\hline Role conflict (for & 0.17 & 0.04 & 0.10 & 0.26 \\
optimism) & 0.23 & 0.04 & 0.16 & 0.32 \\
- ISD & 0.29 & 0.06 & 0.18 & 0.42 \\
M & 0.06 & 0.03 & 0.01 & 0.12 \\
+ I SD & & & & \\
Index of moderated & & & & \\
mediation 2 & & & \\
\hline
\end{tabular}

Notes: Outcome variable, organizational citizenship behavior; Bootstrap sample size $=5000$; Moderated mediation effect I, role conflict moderates the mediation effect of engagement on the relationship between autonomy and organizational citizenship behavior; Moderated mediation effect 2, role conflict moderates the mediation effect of engagement on the relationship between optimism and organizational citizenship behavior.

Abbreviations: $\mathrm{ULCl}$, upper limit of confidence interval; $\mathrm{LLCl}$, lower limit of confidence interval.

fulfilling, positive work-related state of mind can predict organizational citizenship behavior. ${ }^{31}$

This study also suggested that optimism affected organizational citizenship behavior through engagement. A previous study showed that for professional nursing practice, personal resources can influence job performance via work engagement. ${ }^{10}$ Optimistic nurses will believe that life has full of positive things, so unforeseen events and setbacks can always be handled. Nurses with such beliefs have the ability to focus on tasks and complete tasks effectively leading to work engagement. Engaged nurses are more likely to follow to all organizational ethics and standards resulting in practice better organizational citizenship behavior.

We found that the association between autonomy/optimism and work engagement can be moderated by role conflict in this study. A previous research found that job insecurity as a job demand can moderate the relationship between job resources/optimism and work engagement. ${ }^{7}$ Job resources and personal resources have a strong impact on work engagement when job demands are high. Various job demands in the work environment can have a different effect on work engagement. ${ }^{22}$ Challenge demands are beneficial to work engagement and performance, whereas hindrance demands are detrimental to work engagement and job performance. ${ }^{22}$ For instance, a study found role- 
conflict as hindrance demands can affect work engagement negatively. ${ }^{32}$ Bakker and Demerouti argued that individuals may perceive hindrance demands as challenge demands (and vice versa). ${ }^{22}$ One possible reason may be that the effects of various job demands depend on professionals and the context. For example, nurses consider work pressure as hindrance demands because insufficient time makes it impossible to offer patients care, fostering negative events, such as stress and disappointment. ${ }^{22}$

In this study, nurses see role conflict as challenge demands which boost the relationships between autonomy/optimism and engagement and enhance the indirect effect of autonomy/optimism on organizational citizenship behavior via engagement. One possible explanation is that those nurses have a sense of responsibility and collective action, with a high level of solidarity to work. Additionally, the nurses felt very supported by the administration and the community and were given enormous resources to manage the pandemic. Nurses were publicly applauded by the community and the media. Therefore, when nurses are confronted with a complicated situation and conflicting requirements, they perceived role conflict as challenge demands rather than difficulties. ${ }^{22}$ In such a case, autonomy/optimism can be viewed as a coping mechanism, which can constantly change cognitive and behavioral efforts to cope with these demands leading to work engagement and organizational citizenship behavior. ${ }^{9}$ However, if the context is changed, nurses may view role conflict as hindrance demands.

As work engagement has been placed in the central role in the JD-R model, interventions to promote work engagement should be adopted among nurses. ${ }^{33}$ Recovery training and job crafting training can be adopted by organizations to foster work engagement. ${ }^{34}$ For instance, job crafting training courses can raise nurses' awareness about the measures that they can adapt based on personal needs and preferences. Consequently, it helps nurses adjust their jobs and become engaged by using their strengths. Optimizing job demands is also crucial to work engagement. As challenge job demands are regarded as obstacles by nurses to be overcome, these types of demands, such as role conflict and complex tasks, are positively related to work engagement. Organizations should make an effort to provide teaching teams to help nurses combine challenge demands with sufficient job resources to improve their work engagement and job performance. $^{34}$ However, it is important to keep in mind that role conflict may be regarded as hindrance demands if the context changes.

\section{Study Limitations}

Some limitations should be considered in our study. First, it is impossible to conclude the directionality of causal relationships based on this cross-sectional study. Future longitudinal studies are encouraged in order to draw firm conclusions. Second, role conflict was only measured as a job demand. Future studies are encouraged to include different types of job demands in this population. Third, the results are only based on nurses who combat COVID19 in Wuhan, which means that generalization of the findings can be limited. However, as the COVID-19 pandemic continues to spread across the world, this study may provide new insights into nurses' occupational health and job performance in this global pandemic.

\section{Conclusion}

Consistent with the JD-R model, this study found that autonomy and optimism are protective factors to organizational citizenship behavior. The mediation analysis suggests that work engagement can be seen as a mediator between autonomy/optimism and organizational citizen behavior. Moreover, autonomy and optimism help to sustain nurses' work engagement when role conflict is considered as a moderator. The moderated mediation models reveal that the indirect effect of autonomy and optimism on organizational citizenship behavior can be moderated by role conflict.

\section{Ethics Approval and Informed Consent}

This study was approved by the ethics committee of Third People's Hospital of Hubei Province (2020-001). Informed consent from the participants was obtained through the use of click-box agreements on the online survey. This study was conducted in accordance with the Declaration of Helsinki.

\section{Acknowledgments}

The authors thank all participants. Hui Zhang and Yi Zhao are co-first authors for this study.

\section{Author Contributions}

All authors made substantial contributions to conception and design, acquisition of data, or analysis and interpretation of data; took part in drafting the article or revising it critically 
for important intellectual content; agreed to submit to the current journal; gave final approval of the version to be published; and agree to be accountable for all aspects of the work. Hui Zhang and Yi Zhao have contributed equally to this study and share equal first authorship.

\section{Funding}

This work was supported by Health Commission of Hubei Province scientific research project (WJ2021M204).

\section{Disclosure}

The authors have no conflicts of interest.

\section{References}

1. Bakker AB, Demerouti E. Multiple levels in job demands-resources theory: implications for employee well-being and performance. In: Handbook of Well-Being. 2018.

2. Bateman TS, Organ DW. Job satisfaction and the good soldier: the relationship between affect and employee "citizenship". Acad Manage J. 1983;26(4):587-595.

3. Chang CS, Chen SY, Lan YT. Raising nurses' job satisfaction through patient-oriented perception and organizational citizenship behaviors. Nurs Res. 2011;60(1):40-46. doi:10.1097/ NNR.0b013e3181e507dd

4. Islam T, Khan MM, Khawaja FN, et al. Nurses' reciprocation of perceived organizational support: the moderating role of psychological contract breach. Int J Hum Rights Healthc. 2017;10(2):123-131. doi:10.1108/IJHRH-12-2016-0023

5. Schaufeli WB, Bakker AB. Defining and measuring work engagement: bringing clarity to the concept. In: Work Engagement: A Handbook of Essential Theory Research. Vol. 12. 2010:10-24.

6. Hopstaken JF, van der Linden D, Bakker AB, et al. Shifts in attention during mental fatigue: evidence from subjective, behavioral, physiological, and eye-tracking data. J Exp Psychol Hum Percept Perform. 2016;42(6):878.

7. Chen S-L, Shih C-T, Chi N-W. A multilevel job demands-resources model of work engagement: antecedents, consequences, and boundary conditions. Hum Perform. 2018;31(5):282-304. doi:10.1080/ 08959285.2018.1531867

8. Jiang Z, Di Milia L, Jiang YQ, et al. Thriving at work: a mentoring-moderated process linking task identity and autonomy to job satisfaction. $J$ Vocat Behav. 2020;118:103373. doi:10.1016/j. jvb.2019.103373

9. Bakker AB, Demerouti E. The job demands-resources model: state of the art. J Manag Psychol. 2007;22(3):309-328. doi:10.1108/ 02683940710733115

10. Keyko K, Cummings GG, Yonge O, et al. Work engagement in professional nursing practice: a systematic review. Int J Nurs Stud. 2016;61:142-164. doi:10.1016/j.ijnurstu.2016.06.003

11. Luthans F, Youssef CM. Human, social and now positive psychological capital management: investing in people for competitive advantage. Organ Dyn. 2004;33(2):143-160. doi:10.1016/j. orgdyn.2004.01.003

12. Tang Y, Shao Y-F. Psychological capital of MIS development teams, system effectiveness, and social innovation: a systematic literature review. J Front Psychol. 2019;10:1436. doi:10.3389/ fpsyg.2019.01436
13. Crawford ER, LePine JA, Rich BL. Linking job demands and resources to employee engagement and burnout: a theoretical extension and meta-analytic test. J Appl Psychol. 2010;95(5):834. doi: $10.1037 / \mathrm{a} 0019364$

14. Biddle B. Recent developments in role theory. Annu Rev Sociol. 1986;12(1):67-92. doi:10.1146/annurev.so.12.080186.000435

15. Bakker AB, Hakanen JJ, Demerouti E, et al. Job resources boost work engagement, particularly when job demands are high. $J$ Educ Psychol. 2007;99(2):274-284. doi:10.1037/0022-0663.99.2.274

16. Gkorezis P. Principal empowering leadership and teacher innovative behavior: a moderated mediation model. Int J Educ Manag. 2016;30 (6):1030-1044.

17. Hackman JR, Oldham G. Motivation through the design of work: test of a theory. Organ Behav Hum Perform. 1976;16(2):250-279. doi:10.1016/0030-5073(76)90016-7

18. Liu C, Spector PE, Shi L. Cross-national job stress: a quantitative and qualitative study. J Organ Behav. 2007;28(2):209-239. doi:10.1002/ job.435

19. Scheier MF, Carver CS, Bridges MW. Distinguishing optimism from neuroticism (and trait anxiety, self-mastery, and self-esteem): a reevaluation of the life orientation test. J Pers Soc Psychol. 1995;67(6):1063-1078. doi:10.1037/0022-3514.67.6.1063

20. Wen J, Xue F. Dispositional optimism, explanatory style and subjective well-being: a correlation research in college students. Psychol Res. 2011;5.

21. Schaufeli WB, Bakker AB, Salanova M. The measurement of work engagement with a short questionnaire - A cross-national study. Educ Psychol Meas. 2006;66(4):701-716. doi:10.1177/0013164405282471

22. Bakker AB, Demerouti E. Job demands-resources theory: taking stock and looking forward. J Occup Health Psychol. 2017;22 (3):273. doi:10.1037/ocp00000

23. Dong X, Lu H, Wang L, et al. The effects of job characteristics, organizational justice and work engagement on nursing care quality in China: a mediated effects analysis. J Nurs Manag. 2020;28 (3):559-566. doi:10.1111/jonm.12957

24. Moore WE, Gurvitch G. Man, Time, and Society. Wiley: New York; 1965.

25. Peterson MF, Smith PB, Akande A, et al. Role conflict, ambiguity, and overload: a 21-nation study. Acad Manage J. 1995;38(2):429-452.

26. Han Y, Wang M, Dong L. Role conflict and the buffering effect of proactive personality among middle managers. Soc Behav Pers. 2014;42(3):473-486. doi:10.2224/sbp.2014.42.3.473

27. Bachrach DG, Wang H, Bendoly E, et al. Importance of organizational citizenship behaviour for overall performance evaluation: comparing the role of task interdependence in China and the USA. Manag Organ Rev. 2007;3(2):255-276. doi:10.1111/j.1740-8784.2007.00071.x

28. Ding H, Yu E, Chu X, et al. Humble leadership affects organizational citizenship behavior: the sequential mediating effect of strengths use and job crafting. Front Psychol. 2020;11:65. doi:10.3389/fpsyg.2020.00065

29. Hayes AF. Introduction to mediation, moderation, and conditional process analysis. J Educ Meas. 2013;51(3):335-337. doi:10.1111/ jedm. 12050

30. Maurits EEM, de Veer AJE, van der Hoek LS, et al. Autonomous home-care nursing staff are more engaged in their work and less likely to consider leaving the healthcare sector: a questionnaire survey. Int J Nurs Stud. 2015;52(12):1816-1823. doi:10.1016/j. ijnurstu.2015.07.006

31. Christian MS, Garza AS, Slaughter JE. Work engagement: a quantitative review and test of its relations with task and contextual performance. Pers Psychol. 2011;64(1):89-136. doi:10.1111/j.17446570.2010.01203.x

32. Breevaart K, Bakker AB. Daily job demands and employee work engagement: the role of daily transformational leadership behavior. J Occup Health Psychol. 2018;23(3):338-349. doi:10.1037/ocp0000082 
33. Bakker AB, Albrecht SL, Leiter MP. Key questions regarding work engagement. Eur J Work Organ Psy. 2011;20(1):4-28. doi:10.1080/ 1359432X.2010.485352
34. Bakker AB, Demerouti E, Sanzvergel AI. Burnout and work engagement: the JD-R approach. Annu Rev Organ Psychol Organ Behav. 2014;1(1):389-411. doi:10.1146/annurev-orgpsych-031413-091235

\section{Publish your work in this journal}

Risk Management and Healthcare Policy is an international, peerreviewed, open access journal focusing on all aspects of public health, policy, and preventative measures to promote good health and improve morbidity and mortality in the population. The journal welcomes submitted papers covering original research, basic science, clinical \& epidemiological studies, reviews and evaluations, guidelines, expert opinion and commentary, case reports and extended reports. The manuscript management system is completely online and includes a very quick and fair peer-review system, which is all easy to use. Visit http://www.dovepress.com/testimonials.php to read real quotes from published authors. 